\title{
A Survey on Role of Intelligent Community and Social Networking to Enhanced Learning Process of Students and Professionals
}

\author{
Adarsh S. Patel \\ Assistant Professor, Parul \\ Institute of Engineering and \\ Technology (MCA), Vadodara.
}

\author{
Hiren Darji \\ Assistant Professor, Anand \\ Institute of Information Science, \\ Anand.
}

\author{
Jahnavi A. Mujapara \\ Visiting Lecturer in \\ Mathematics Department, \\ Bhavnagar University, \\ Bhavnagar.
}

\begin{abstract}
Social website has changed our world of learning for all people. Students and professional are using social networking websites to share day to day activity and learn new things because, it provides features like uploading and sharing photo, sending and receiving messages and searching and connecting friends and communities and much more. The social websites enables people to be active and selective in their exposure to communicating and sharing. [1] Business has also started using social websites to market their products and sharing of business information and online learning. In recent days, internet presence has changed the whole world of learning over the internet using social networking and intelligent community. A community is an interconnected group of people with similar interest on social networking websites and is known as group or page. Intelligent community plays a very significant role to create, share and reuse the knowledge which can be used to learn new trends. The aim of this research paper is to show how intelligent community and social networking websites are useful for students and professions. In this paper we have discussed facility provided by the social website, intelligent community and how it is useful to enhance learning process for both students and professions. [1][6].
\end{abstract}

\section{Keywords}

Learning Process, Intelligent Community, Social Website Impact.

\section{INTRODUCTION}

In today's world social networks are one of the major providers for communication for people across geography. Social networking is utilized by all human being, starting from young generation to elders. Social networking is a platform to collaborate, share comments or create a group or community for people of similar behavior. Students has started using social networking websites for learning new technology to stay tuned with their interested communities and sharing their personal views on it. So this group of people sharing their views on same topics is communities in social networking terms, but if it has a specific goal designed then it is turned into Intelligent Communities! Currently teachers are teaching using board and chalk and using one or more books that are available, but this techniques required much time and learning process can be slow, while using intelligent communities students can able to know more in less time using graphics, video shared on communities or by using social networking.[6] Businessmen has started creating facebook pages or group for sharing their business process and communications along with all business staff members.
They are promoting their business by inviting their friends and employee and making promotions and sharing advertises of new product launched. Even they can be in touch with their clients also and can solve their query or can help immediately by using special community blog or social circle. Other way to stay in touch with your client is to just post a small message on your twitter account and your client can get updated with latest product launched by your company it is called as micro blogging.[4][3][11].

\section{SOCIAL NETWORKING}

Social Networking has attracted most of the internet users by providing a platform to communicate with the people by sharing their day to day activity. Social networking websites are proving a powerful medium to build up public relations. it can be utilize to encourage new learning, brand awareness, develop consumer relations and increase brand loyalty. Social networks can enable practitioners to influence consumers and engage users in a brand, becoming a mutually beneficial relationship. [2]

As per the review provided by the world ranking website alexa, Facebook is at $2^{\text {nd }}$ position. Let's see the major features provided by the facebook. Facebook is very popular social website in world. It provides facility to built up virtual relations with free of cost and can be used by a person, business or a brand. It provides different features for different categories. Facebook was started on February 4, 2004 and now having 1 billions of users worldwide and having 1st rank as per alexa. Major features provided by Facebook are as follow: a) Search Friend: It provides facility to search our friends by using different features like from our address book, from our past school, colleges or colleagues or area. Friend is the basic requirement for facebook to keep alive and it creates more interactions and hit on the websites. b) Business promotions: If you owned business you can create a page for your business and can post every event on that page. c) Low cost or free advertising: Facebook provide a business owner with the opportunity to advertise to a very specific demographic region for very less money. So you can advertise to exactly the customer that you want to attract and save money versus other forms of advertising. even you can post in your business page that is totally free of cost and your follower can get information about your latest products and plans) Build up your presence: By constantly interacting and posting a person can build trust and credibility among their audience which in turn can lead to more business. e) Easy and free communication: facebook allows you a fast and free resource for learning and communicating for students and 
professions. There is some privacy issue in facebook, which are beneficial for businessmen. [5]

Another social networking tools for micro blogging that is Twitter. Twitter is popular social networking provides facility to post message on the board and followers can view our message and can repost to their board or can make comment on it. It was introduced on March 21, 2006 and now having approx 500 millions of users and their worldwide rank is 8 as per alexa. Now a days major celebrity has started using twitter to share their views on the every event. Twitter can be utilized for much way to stay tuned with people while we can learn and get opinion from others too. A student is reading from the textbook and found some difficult points to understand, So he immediately tweets his question to the Twitter community, and gets three responses within ten minutes), two responses from classmates, and one from their faculty[3].

\section{INTELLIGENT COMMUNITIES}

A community with a specific goal is known as Intelligent Communities. People have started communities on social networking websites and they are adding only selected people into those communities for communication purpose. Social networking website provides virtual connections between two or more users. [6]

Some of the basic characteristics of intelligent communities includes Find and stay connected with the right practitioners, with the right skills, Identify appropriate peer groups and rapid collaboration, Build skills mentoring and share knowledge through virtual collaboration, Reduce efforts significantly by obtaining the correct information, Cross hierarchy or organizational structures independently.[7][19]

Facebook provides the group and page functionality. By using facebook page you can create your brand or product page, you can connect with people and communicate easily. Facebook book page provides like and share feature to easily look for new people and share knowledge among. Here you can create intelligent page or group by providing the more information related to group.

Twitter is also providing the way to share small set of information. By using twitter you can post in special category using hash tag. Another method you can post cross post to another peoples wall by using at tag. So in twitter you can create the profile and can share information among the interested people.

\section{CURRENT LEARNING PROCESS}

Learning is the process of getting new ideas or theory. Learning is very essentials for every human being. Current learning process includes classroom learning or workshop learning; it depends on many factors like environment, style of learning, classroom condition, etc. Current learning process includes techniques like positive relationships, cooperative engagement, active learning, constructive feedback mutual respect, teacher as responsible educator, etc.

In current learning process, we are using the traditional method to learn new things. Some people are using facebook and twitter for learning but here they are not aware with the intelligent communities. So by this method learning is very slow and it takes more time to learn new things.

Drawback of current learning process is it creates more stress, by using current learning techniques employee gets lots of stress, to solve all this problems we need to move towards the new kind of learning process. [18]

\section{FUTURE LEARNING PROCESS FOR STUDENTS}

In near future learning process can be changed from classroom to online lectures with the use of latest technology, for the development of new latest learning process so many social networking websites are providing free and easy methods. Here we will discuss most popular two websites which can be used for future learning. [8][9][14]

Facebook can be used for learning process, as faculty or teacher can have their page or group, where users can start conversations on topics, the members of that group can post their answers/queries and can talk with each other in details. Facebook provides very powerful features like sharing of photo and video can be used for enhanced learning process, teacher can share their pre recorded video for a group member so students or group member can able to view it and can learn. Students can get benefit of the social networking by asking some question over the Facebook website via personal message or message to group of people and can get solutions very quickly. Facebook is available on different platform i.e. website on computer, access via SMS or mobile. So people are having any medium can access it and can learn $24 \times 7$. Even teacher can low cost advertising for their publicity or can link their Facebook page with some other website for increasing popularity. [13][16]

Twitter is very powerful tools for micro blogging. Here user can post about 140 characters and can get immediate reply on it. We can edit post online or can be sent via SMS or email. Twitter can be utilized to create awareness about new technology and news. [12] Tweets are publicly visible by default, but senders can restrict message delivery to just their followers. Users can tweet via the Twitter website, compatible external applications that we have to register is once. [3][10]

\section{FUTURE LEARNING PROCESS FOR PROFESSIONALS}

Professionals has already started using social networking to learn new every day without any kind of stress, social networking is better way to communicate across a group of people with fun. Nowadays professionals has started using facebook pages and groups to create social network presence and using social network to share their company information and sample documents.

Facebook is providing page and group facility for the professional, page is used to make presence of the company. People can search for the pages related to their interested company pages, which provides latest information related to their interest of learning.

Twitter is used to post small messages related to updates of company, it is also called as micro blogging. Twitter can be used via many platforms. For example you can post message to twitter account via sending SMS to specific gateway or can be accessed using api provided by the twitter. [3][10][17]

\section{SURVEY RESULT}

As we have created one survey over internet to collect some basic analysis regarding our research topics. Here is the result of the same. Total response we have received is 226 . Out of this response $210(93 \%)$ are using social networking websites and $16(7 \%)$ are not using social networking websites. Out of this $151(67 \%)$ is students while others are $59(33 \%)$ businessmen or others. Out of total response $156(69 \%)$ is daily users of the social networking websites while $46(20 \%)$ are weekly users and remaining are $11 \%$ are visiting social 
networking very less. Out of total response $196(87 \%)$ is a member of any social networking groups this can be intelligent communities while $30(13 \%)$ are not a member of any group. Finally we conclude based on survey that $163 / 210$ (77\%) using for Learning, 137/210 (65\%) for Education, $70 / 210(33 \%)$ using for advertisement.

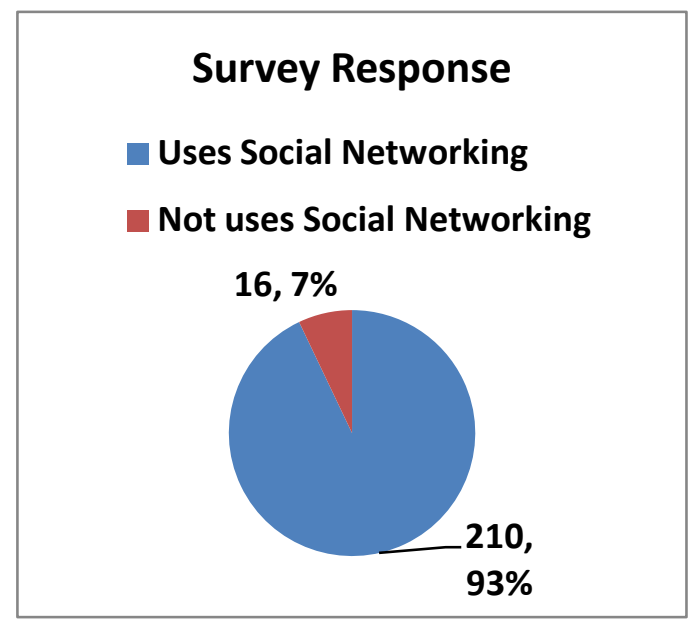

Figure 1 : Total Survey Response

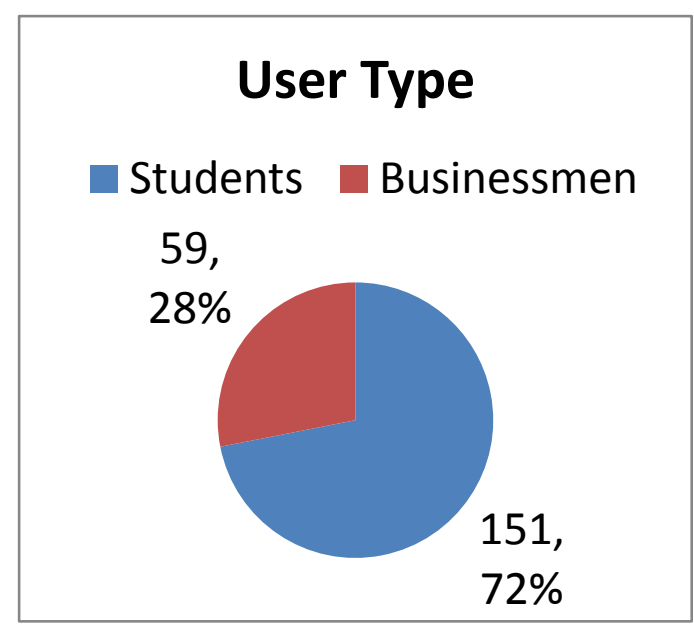

Figure 2 : Types of Users

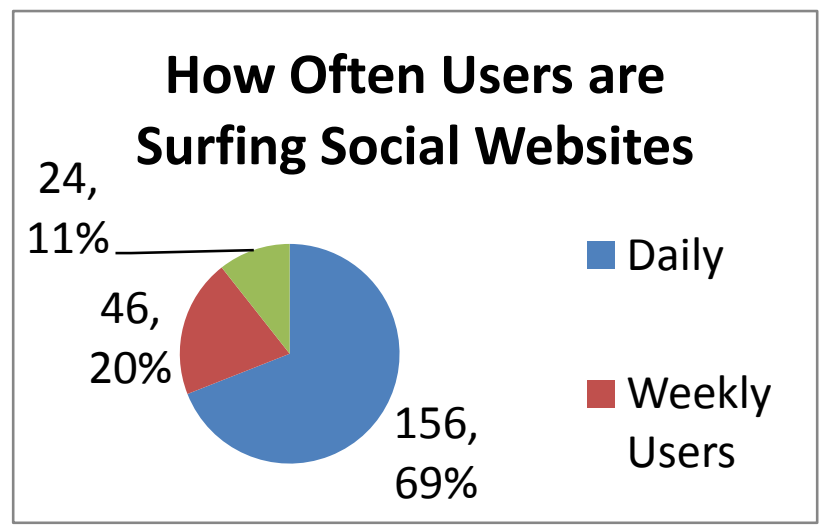

Figure 3 : Survey Ratio

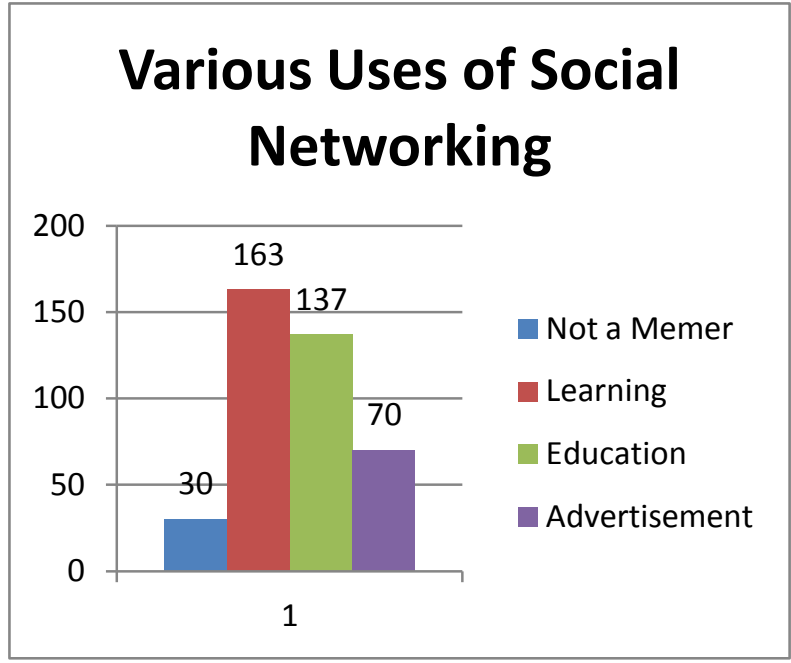

Figure 4 : Users of Social Network

\section{CONCLUSION}

In this paper we conclude that there are many possibilities for learning using intelligent communities of social networking for students and professionals. Current learning process includes basic technique like whiteboard or blackboard learning process. While in future social networking will change the way of learning by providing their amazing facility. Nowadays people has started developing intelligent communities to communicate and to learn, this will be very much easier for the students and businessmen to enhance their learning process, It includes day to day working style or can be process of the working machine, etc.

Current social networking website provides some of the common features for students, these features can be improved by attaching some important features like submission of assignments, result declaration, student progress report. This kind of features can be useful for the teachers to communicate with students on the social platform including preparation of the student progress report also.

For professionals social networking website provides a number of features like group, pages. By using these features professional can learn the more about their interest.

At the end we would like to say that based on our small survey we can get the details that nowadays people has started using social networking for learning. Around $69 \%$ of the users from our survey people are using social networking daily while $20 \%$ uses are the weekly users and remaining are very rare visitors. Another analysis that around 163 people out of 226 are uses social networking for the learning purpose. So based on our survey, people has started social networking to learn new technology.

\section{ACKNOWLEDGMENTS}

We are thankful to the faculty and experts who have helped us to prepare research paper. We are also thankful to all the users who has fill up our survey and help us to prepare a small statistical report.

\section{REFERENCES}

[1] Alessandro Cecconi, "Research Paper on Social Networking: Research Paper on Social Networking".

[2] Ashleigh McLennan , Gwyneth V.J. Howell , "Social networks and the challenge for public relations". 
[3] Bernard J. Jansen and Mimi Zhang, Kate Sobel, Abdur Chowdury, "Twitter Power:Tweets as Electronic Word of Mouth", 2009.

[4] Carmen Holotescu , Gabriela Grosseck , "Using microblogging to deliver online courses. Case-study" , January 4, 2009.

[5] Catherine Dwyer, Starr Roxanne Hiltz, Katia Passerini, "Trust and privacy concern within social networking sites: A comparison of Facebook and MySpace", August 09-12-2007.

[6] Diptiman Dasgupta and Rudranil Dasgupta, "Intelligent Communities and Future of Social Networking", CSI Communications, April 2012.

[7] Dr. Naresh Patel, "Internet based viral marketing for global competition: The road ahead", IIMK.

[8] Dr. Qais Faryadi, "Effective Teaching and Effective Learning: Instructional Design Perspective”, IJERA Vol. 2, Issue 1, Jan-Feb 2012, pp.222-228.

[9] Fiona Redmond , Dr. Deirdre Lillis , "social networking sites: evaluating and investigating their use in academic research ".

[10] Gabriela GROSSECK, Carmen HOLOTESCU , "can we use twitter for educational activities?", April $18^{\text {th }} 2008$.

[11] Joanna C. Dunlap , Patrick R. Lowenthal , "Instructional Uses of Twitter", 2008, February.
[12] ] Joanna C. Dunlap , Patrick R. Lowenthal , "Tweeting the Night Away: Using Twitter to Enhance Social Presence", 2009.

[13] Mabel AlvarezAlvarez , Tatiana Delgado Fernndez , Rafael Cruz Iglesias, "Social networks and Web 2.0 tools as a good complement to the local SDIs".

[14] N. Kiran Kumar,Prof. C. Rajendra, "Cloud E-Learning: A New Virtuous Business Archetype for E-Learning", IFRSA's International Journal Of Computing Vol 2 issue 3 July 2012.

[15] Online: http://www.theintelligentcommunity.com/.

[16] P. Sri Jothi, M. Neelamalar,R. Shakthi Prasad, "Analysis of social networking sites: A study on effective communication strategy in developing brand communication ", Journal of Media and Communication Studies Vol. 3(7), pp. 234-242, July 2011.

[17] Sitaram Asur , Bernardo A. Huberman , "Predicting the Future With Social Media".

[18] Shilpi Johri,"Stress As a Preventive Mechanism for Learning and Development", IFRSA Business Review Vol2 issue 3 Sep 2012.

[19] "What Is The Reason For An Intelligent Community?", November 4, 2008. 